\title{
Upgrading the Old Traditional Neighbourhoods in Nigerian Cities: A Case Study of Oke-Itoku Area of Abeokuta
}

\author{
Oguntimehin, Abiodun Sunday ${ }^{1}$, Bamidele, Ebenezer Olutide ${ }^{2}$ \\ ${ }^{I}$ Department of Architectural Tech., School of Environmental Studies, Federal Polytechnic Ilaro, Ogun State, \\ Nigeria. \\ ${ }^{2}$ Department of Building Techn., School of Environmental Studies, Federal Polytechnic Ilaro, Ogun State, \\ Nigeria.
}

\begin{abstract}
The decay of Nigeria traditional neighbourhood is a result of uncontrolled population and physical growth. Coupled with this problem, is the total neglect of renewal and maintenance as at when due which eventually led to unplanned development, inadequate provision of social services, as well as infrastructural facilities and environmental degradation. This paper therefore investigates the old traditional neighbourhoods in Oke-Itoku area of Abeokuta, using a well structured questionnaire administered to the residents of the Neighbourhood with a view to finding out the conditions of buildings in the area and how it could be improved. Data gathered from the field work were statistically analysed using various statistical tools such as frequency tables, Pie charts, Line chart and Bar Chart. Findings from the work show that $58.80 \%$ of the buildings in the study area are not in good condition and in as such the need for upgrading is essential. In order to achieve sustainable development, there is the need to make the old traditional neighbourhoods of Nigerian cities functional, livable and of good quality; and every house owner, public agencies, private agencies as well as non-governmental organizations have a role to play in this direction.
\end{abstract}

Keywords: Building, Traditional Neighbourhood, Upgrading, Urbanization, Urban Renewal

\section{Introduction}

Nigeria is developing at a tremendous pace. Rapid economic development and urbanization have led to an enormous amount of construction activity in terms of new urban districts, but also with demolition and redevelopment of inner city areas.

A successful urban planning agenda will require that attention be given to urban settlements of all sizes. If well managed, cities offer important opportunities for economic development and for expanding access to basic services, including health care and education, for large numbers of people. Providing public transportation, as well as housing, electricity, water and sanitation for a densely settled urban population is typically cheaper and less environmentally damaging than providing a similar level of services to a dispersed rural population. (Olokesusi, 2004).

The phenomenal rise in number and size of Nigerian cities has over the last few years resulted in several problems and urban crisis. Among these are acute shortage of dwelling units which have resulted into overcrowding, high rents and slum settlements and inadequacies both in terms of quality and quantity of lifesupport systems e.g water, medical facilities and infrastructure such as sewers, roads, electricity, parking, communication facilities, waste disposal problems etc. studies have shown that urban facilities are already congested and polluted thus indicating poor environmental quality (Onokerhoraye, 1986; Sada, 1980; Omuta, 1983; Olokesusi 1986; Akintola and Nyama, 1978). However, urbanization is not a new phenomenon in Nigeria. It dates back to the pre-colonial period. Even though, demographic estimation is contentious in Nigeria, all available indices suggest that urban growth has continued unabated (Onibokun, Olokesusi and Egunjobi, 1986; Onokerhoraye, 1986). Urban population growth in Nigeria can be seen as a process of pre-colonial origin initiated by trade and military conquest. This situation was aggravated by driving forces of export, transportation technology and the rule and discriminatory policy for the location of public utilities and services and economic activities during the colonial period and the national development plan creation of states of the post independence period. The distribution of amenities and economic opportunities are lopsided in favour of the urban centers of the country. In Nigeria urban settlement, the problems associated with population concentration will be categorized here as follows:

i. The transference of rural problems that include: poverty illiteracy and unemployment through migration to urban centers.

ii. The rapid congestion of population that influence inadequacies in the areas of facilities and utilities and the problem of uncontrolled physical growth of the residential areas.

The failure of urban settlement to provide employment opportunities for the migrants has led to their poor environmental and physical conditions. Unemployment in these centers are cause by progressive migration at 
high rate and low rate at which employment opportunities are being provided. This led to high rate of delinquency, criminality and urban poverty. (Odunjo, Baba and Adeoye, 2006)

The low level of housing shortages and hence overcrowding and the consequent stress and strain available facilities, services and utilities. A study carried out by Onibokun et al (1986) shows that about $67 \%$ of the houses in Nigeria require minor or major repairs.

The pace of development in the urban centers has therefore been such that maintenance of modest environmental standard inevitably had to lag behind and these problems are more pronounced in the old traditional neighbourhoods of urban settlements in Nigeria.

The 1992 Earth summit conferences identified promotion of adequate shelters for all as one of its eight programmed area as it was observed that many developing countries are characterized with inadequate shelters broth in term of quality and quantity. Consequently, the failure of urban settlement in Nigeria to provide adequate shelter for the city dwellers call for the need to upgrade the old traditional neighbourhoods of Nigerian cities in order to complement the existing housing stock.

\section{Statement of the Problems}

Despite wide attention giving to housing issues, the problem of housing still persists (Hamdi, 1995) Governments policies aimed at solving these problems have not succeeded both (Oluwoye and Olayiwola, 2006). It is the general conclusion that housing situation is generally poor, especially in the Old Traditional Neighbourhood of Nigeria Cities.

The housing situation and condition of a city is usually measured in terms of the housing quality of the various segments in the city (Olatubara, 2003). Such quality which is either ranked as low, medium or high or good, fair and poor has led to various determinants and preferences in housing locations in the state. (Oguntimehin and Oguntimehin, 2017)

The old traditional neighbourhoods of Nigerian cities no longer encourage people to live in the because of deteriorating condition of buildings, environmental pollution, unsanitary environment, lack and poor supply of facilities and amenities and poor disposition of buildings with poor ventilation and day lighting. These Neighborhoods also serve as hide outs for criminals. (Oluwoye and Olayiwola, 2006). In Yoruba land, the old neighbor hoods are dominated most places by old buildings, some of which are either dilapidated, unmaintained or abandoned. These old traditional neighbouhoods are mostly inhabited by low income earners and the employment that are otherwise known as the urban poor who cannot afford to pay high rents for better houses when they are available. These neighbourhoods also suffer high rates of out-migration of the productive youth.

\section{Aim and Objectives}

The aim of this study therefore is to appraise the present situation of old neighbourhoods of Nigerian cities using Oke- Itoku area of Abeokuta as a case study with a view to upgrade the standard of living of the area to meet the present day requirements and estimated future needs of the residents.

To achieve the stated aim, the objectives are to:

(i) Examine household characteristics in the study area (ii) assess the conditions of buildings within the area (iii) assess the socio-economic characteristic of the people

\section{The Old Traditional Neighbourhoods Of Nigerian Cities}

A neighborhood is a Geographic area with people living close to one another or a neighborhood is generally a localized section within a larger city or suburb. A neigbourhood is a secondary level in hierarchical concept of a town. This is in view of the fact that a town is a supplier of high services while the neighbourhood is a supplier of lower services. Keeble(1969). Neighbourhood is a locality with variable definitions depending upon the perception of the residents i.e. "the region where one lives". As a concept, it has various definitions but basically, it can be describe as that locality where there exists a complex social relationship between individuals and family groups and a degree of social interdependence i.e. kinship or friendship ties. According to Challans (1974), neighbourhood is a planned physical unit, which embodies sufficient social and service facilities to make it practically self contained.

Rapid urbanisation in developing countries in Africa is not commensurate with economic development compared to developed world (UN-Habitat, 2004).The rise in population is predicted to have adverse effects on the quality of urban life because of the inability of real estate developers and governments agencies to keep pace by providing adequate housing, and requisite infrastructure and social facilities (Limbumba, 2010).

The deteriorating condition of these neighbourhoods is however not the fault of the inhabitants alone simply because of poverty, ignorance and lack of willingness to maintain and invest in them but also partly on the government for her neglect on the provision of infrastructure, formulation of appropriate development control measures for buildings as well as failure to formulate a National Urbanization Policy within the frame work of the National Development Plan to alleviate poverty and social isolation of the majority groups in the 
core and old areas of cities. Consequently, there is an urgent need to relieve the old traditional neighbourhoods of these problems particularly if housing problems are to be ameliorated in the urban areas as well as in order to blend with the other parts of the city. For instance, it is important to retain and protect the architectural values, cultural heritage of the peoples and their original values as center of life including trading activities in the cities.

\section{The Study Area}

Oke- Itoku area is one of the old traditional neighbourhoods of Abeokuta city and is located very close to the Olumo rock, a predominant historic features and Tourist landmark in Abeokuta, Ogun State. The area is characterised by the major problems that are typical of traditional neighborhoods in the Old City. Sanitary conditions of the houses in the area are often poor, individual toilets or bathrooms are often missing. Most of the residents still use public toilets. The physical condition of the housing is generally deteriorated, and desperately needs repair and upgrading. This area is chosen because it is characterized with the problems described above.

Furthermore, the residents do not want to leave their roots and even if these conditions are allowed to continue unchecked, the traditional area of cities may one day show a total functional and physical collapse. Hence, there is need for upgrading.

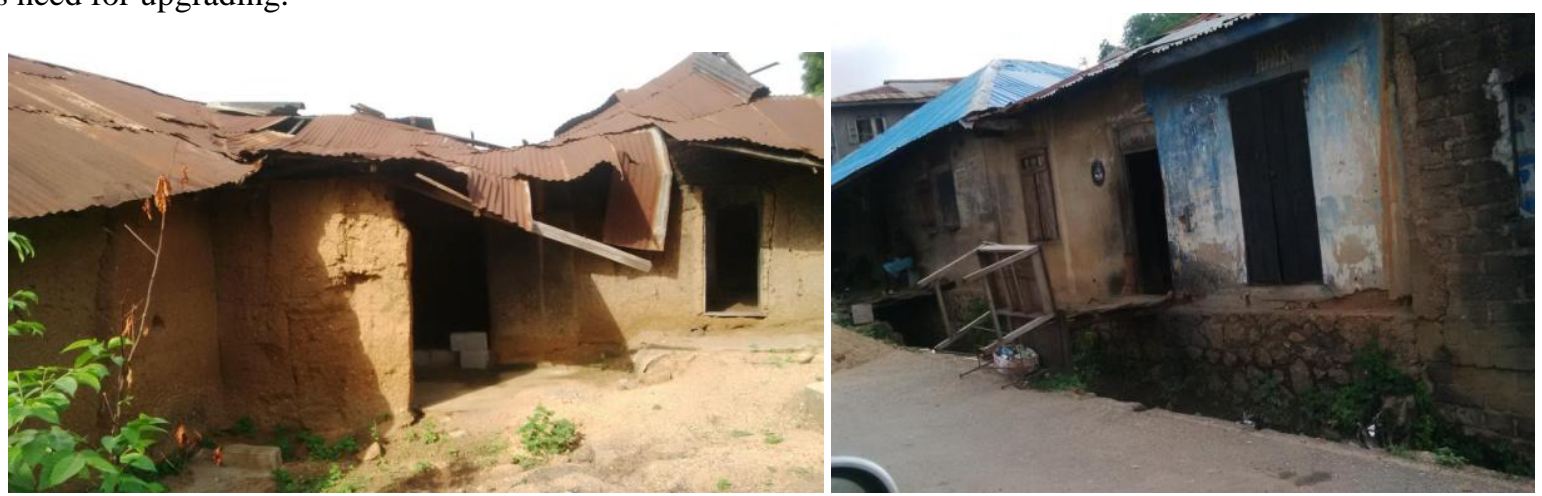

Plate 1: Picture showing building condition of resident. Plate 2: Building with Zero set back from road. Source: Researcher's Field survey, 2017.

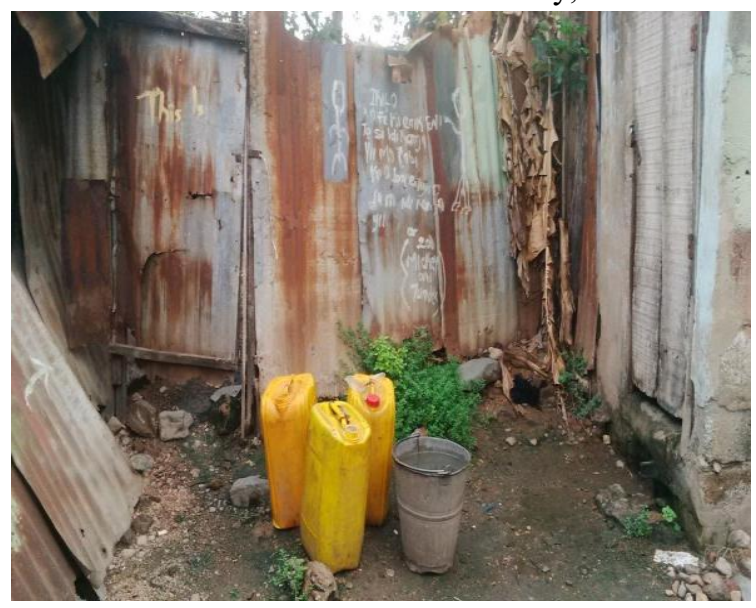

Plate 3: Picture showing water source beside toilet Source: Researcher's Field survey, 2017.
Source: Researcher's Field survey, 2017.

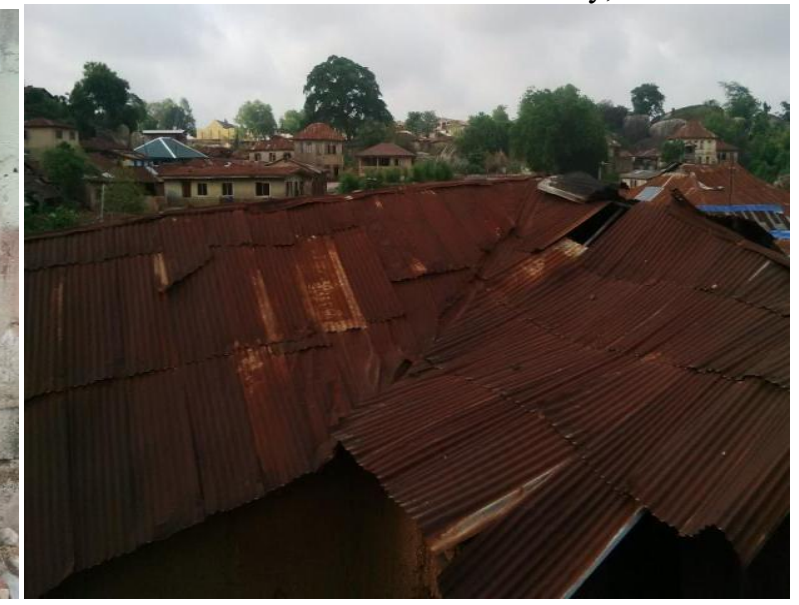

Plate 4: Picture showing the roof condition in the area. Source: Researcher's Field survey, 2017.

\section{Research Method}

Data Source: Required data were from primary and secondary sources. The primary data were obtained through questionnaires and were complemented with oral interviews of occupiers of Residential properties involved in the study. Secondary data were obtained from textbooks, Journals etc.

The questionnaire was divided into two parts: environmental survey and socio-economic survey.

i. Socio-Economic Survey: Questions were asked on the socio-economic characteristics of the area and the dwellers. Such information includes size of household, level of Education and demographic characteristics.

ii. Environmental Survey: This covered the physical characteristics of buildings in and the area. Information were collected on facilities provided within, percentage of derelict and near derelict buildings taking into account such indicators as condition of the walls, floor, roof, age of buildings and general outlook of the building as well as the extent of deterioration. Assessment of all these variables was made by visual observation. 


\section{Research Sample and Sampling Techniques}

In the choice of the population for this study, the researcher used simple random sampling technique. This technique provides each member of the entire research population equal and independent chance of being selected or included in the sample. Another reason why the researcher chose this technique is that it is simple and easy in terms of conceptualization and application. Techniques like tables and charts were used as a means of showing responses from respondent's variations of the element.

The techniques were used in selecting 176 households in the neighbourhood and 148 household heads responded effectively giving $84.09 \%$ which is sufficient for valid assessment of the situations under study. The statistical analysis used include descriptive statistics as percentage and frequency Counts.

\section{Data Analysis And Presentation Of Results Questionnaire Distribution}

Table1: Number of Questionnaires Administered and Retrieved.

\begin{tabular}{|l|l|l|l|}
\hline Respondent & Number Distributed & Number Retrieved & Percentage (\%) \\
\hline Residents & 176 & 148 & 84.09 \\
\hline Total & $\mathbf{1 7 6}$ & $\mathbf{1 4 8}$ & $\mathbf{8 4 . 0 9}$ \\
\hline
\end{tabular}

Source: Researcher's Field survey, 2017

Socio-Economic and Characteristics of the Respondent

Table 2: Respondents Sex Distribution

\begin{tabular}{|c|c|c|c|}
\hline$\overline{\text { Sex }}$ & Frequency & Percent & Cumulative Percent \\
\hline Male & 118 & 79.72 & 79.72 \\
\hline Female & 30 & 20.28 & 100.0 \\
\hline Total & 148 & 100.0 & \\
\hline
\end{tabular}

Source: Researcher's Field survey, 2017

Table 3: Respondents Age Distribution

\begin{tabular}{|c|c|c|c|}
\hline Age & Frequency & Percent & Cumulative Percent \\
\hline \begin{tabular}{l|l|} 
& $0-20$ \\
\end{tabular} & 12 & 8.11 & 8.11 \\
\hline $21-40$ & 34 & 22.97 & 31.08 \\
\hline $41-60$ & 73 & 49.32 & 80.40 \\
\hline 61 and Above & 29 & 19.59 & 100.0 \\
\hline Total & 148 & 100.0 & \\
\hline
\end{tabular}

Source: Researcher's Field survey, 2017

\begin{tabular}{|l|l|l|l|l|}
\hline \multicolumn{4}{|c|}{ Table 4: Respondents Educational Qualification } \\
\hline Educational Qualification & Frequency & Percent & Cumulative Percent \\
\hline SSCE & 57 & 38.51 & 38.51 \\
NCE/OND & 22 & 14.86 & 53.37 \\
\hline HND/B. Sc. & 57 & 38.51 & 91.88 \\
\hline M. Sc. & 12 & 8.11 & 100 \\
\hline Ph. D & 0 & 0 & 100.0 \\
\hline Total & $\mathbf{1 4 8}$ & $\mathbf{1 0 0 . 0}$ & \\
\hline
\end{tabular}

Source: Researcher's Field survey, 2017

Socio-Economic and Characteristics of Oke-Itoku area of Abeokuta.

Table 5: Accommodation density

\begin{tabular}{|l|l|l|l|}
\hline Persons per House & Frequency of response & Percentage & Cumulative \\
\hline $\mathbf{1 - 1 0}$ & 12 & 8.10 & 8.10 \\
\hline $\mathbf{1 1 - 2 0}$ & 25 & 16.89 & 24.99 \\
\hline $\mathbf{2 1 - 3 0}$ & 45 & 30.41 & 55.40 \\
\hline $\mathbf{3 1 - 4 0}$ & 66 & 44.59 & 100 \\
\hline TOTAL & $\mathbf{1 4 8}$ & $\mathbf{1 0 0}$ & \\
\hline
\end{tabular}

Source: Researcher's Field survey, 2017 
Figure 1: Bar Chart showing Household size in Oke-Itoku

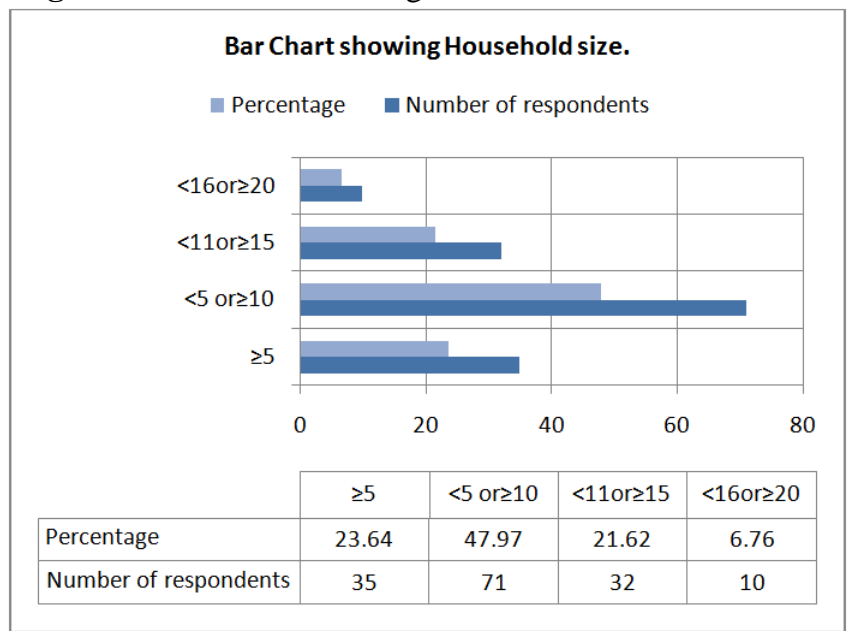

Source: Researcher's Field survey, 2017

\section{Conditions of Building within the Area}

The quality of each house in the area was assessed based on the assessment of variables such as availability of water, toilet, accessibility to house etc. Each variable was scored and later summed up, then, different range arrived at for classification of house into poor, fair and good.

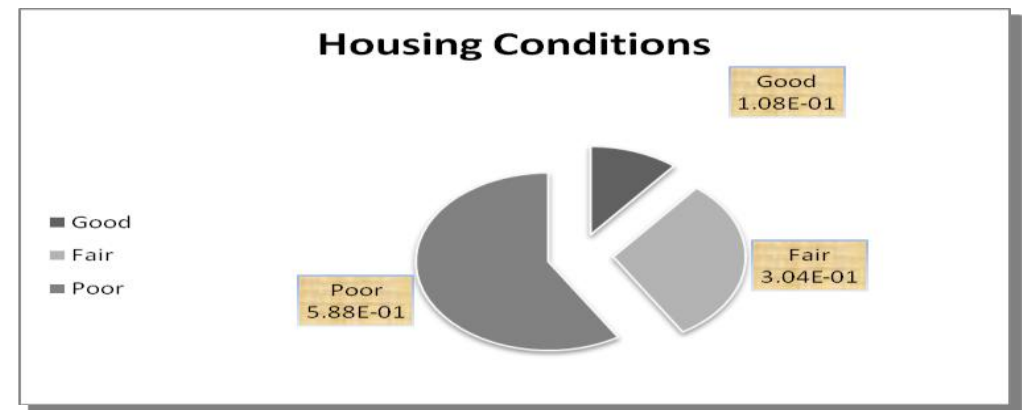

Figure 2: Pie Chart showing General Housing Conditions in Oke-Itoku area of Abeokuta. Source: Researcher's Field survey (2017).

Figure 3: Bar Chart showing the state of the Building Facilities in Oke-Itoku area of Abeokuta.

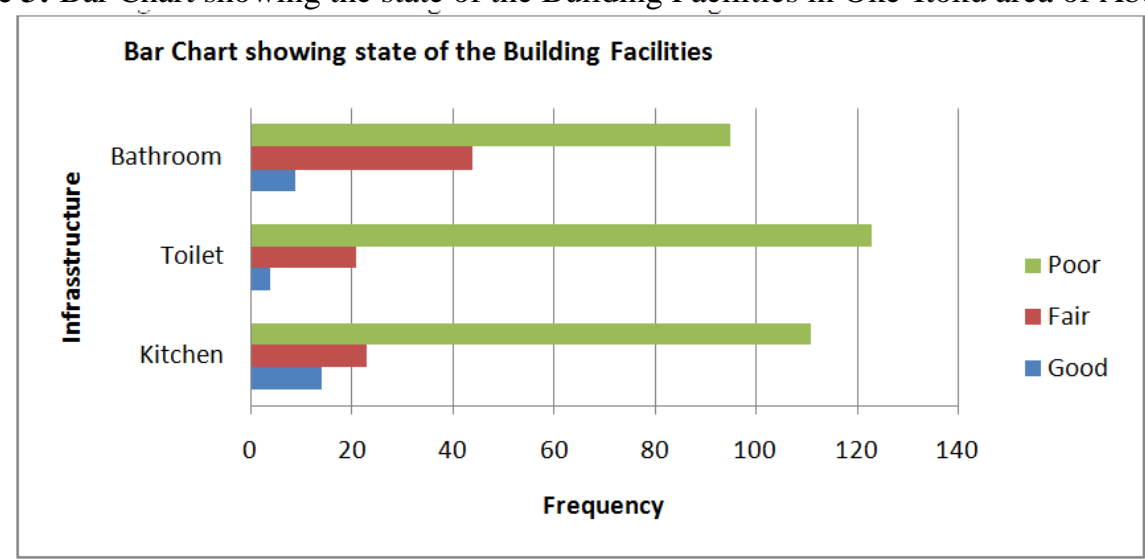

Source: Researcher's Field survey (2017). 
Figure 4: Line Chart showing the state of the Building Components in Oke-Itoku area of Abeokuta.

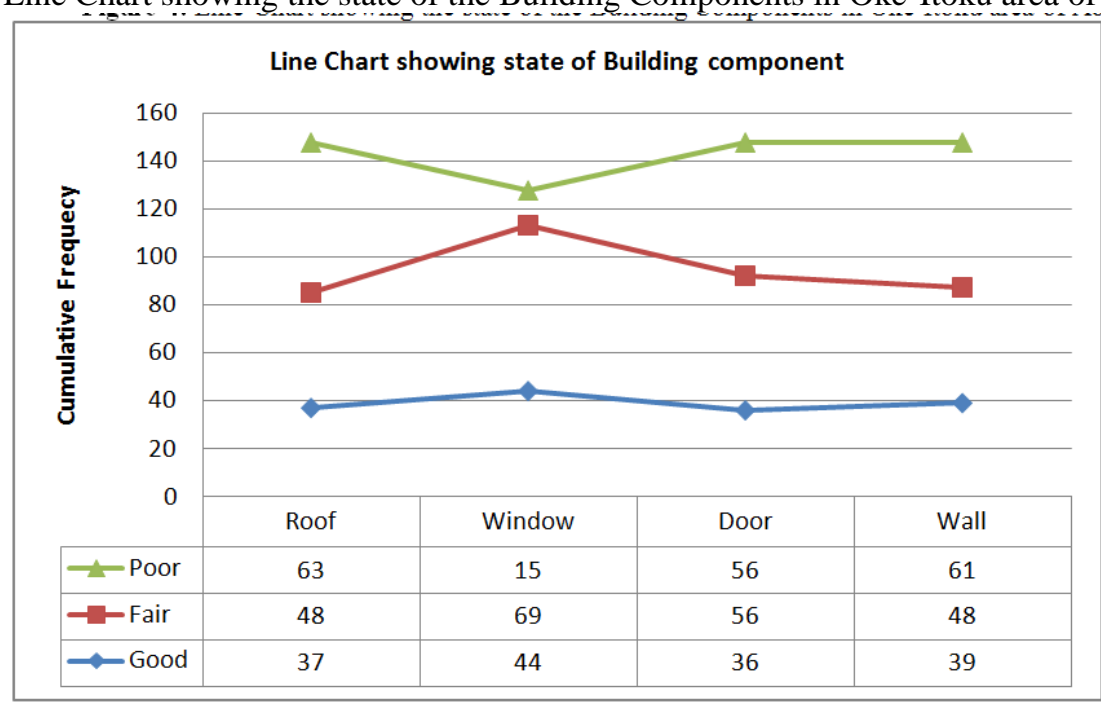

Source: Researcher's Field survey (2017).

\section{Discussion Of Findings}

Out of the 176 questionnaires administered to Residents in Oke-Itoku area of Abeokuta, 128 were retrieved which represent $84.09 \%$ which is sufficient for valid assessment of the situations under study.

The sex distribution and age distribution of the respondents show that $79.72 \%$ are males while $20.28 \%$ are females which show an adequate gender distribution and avoid any form of gender inequality. Also, the respondents within the age bracket of 41-60 years as shown in the table 3 have the highest percentage of $49.32 \%$, followed by those between $21-40$ years representing about $22.97 \%$. Those within the age bracket $0-20$ years constitute $8.11 \%$ while those between 60 years and above constitute about $29 \%$.

The research also revealed that respondents with HND/B.Sc and SSCE represents the highest percentage of $38.51 \%$, while those with M.Sc represents $8.11 \%$ while those with NCE/OND and Ph.D represents $14.86 \%$ and $0 \%$ respectively. This clearly shows that the set of respondents possess the relevant educational background for derivation of adequate and certified information as regards the study and hence, their opinion can be adequately relied upon.

Table 5 shows the Demographic Characteristics of respondents per house. From the table, 31-40 per house has the highest frequency and represent $44.59 \%$, followed by $21-30$ per person per house which represent $30.41 \%$, while $11-20$ and $1-10$ represents $16.89 \%$ and $8.10 \%$ respectively.

The household size of respondents is shown in Figure 1. The highest house hold size is the 6-10 persons with frequency of 71 which represent $47.97 \%$, followed by household 1-5 with frequency of 35 which represent $23.64 \%$, while household $11-15$ and 16-20 have frequency of 32 and 10 and represents $21.62 \%$ and $6.76 \%$.

The Housing condition of Oke-Itoku as reveal in Figure 2 shows that, $58.8 \%$ of the buildings are in a poor state while $30.4 \%$ are fair, only $10.8 \%$ could be pointed to as buildings in good condition.

The building facilities in the Neighbourhood was also analyzed as shown in Figure 3, the analysis reveals that the bathroom, toilets and kitchen are in poor state with percentage of $57.03 \%, 81.75 \%$ and $75 \%$ respectively. These show that toilets facilities in the area are extremely poor. $34.38 \%, 14.19 \%$, and $15.54 \%$ are in fair state respectively, while $8.59 \%, 4.05 \%$ and $9.45 \%$

Majority of the fair buildings are structurally sound as revealed by the walls perimeter, ceiling and the roof. These building only lack facilities attached to house such as toilet, kitchen and bathrooms and in a situation where these facilities are provided; they are substandard. This lowered their scores and makes them fall within the range of fair buildings. However, the buildings that are in poor condition are many and this is due to lack of maintenance and age. The buildings in fair conditions need either minor or major repairs to upgrade their standard and this will involve mostly the provision of adequate facilities.

Also from figure 4, this shows the condition of the building components in the area. The Roof has $42.57 \%$ as poor, $32.43 \%$ as fair and $25 \%$ as good, while the Windows has fair as the highest percentage of $46.62 \%$, follow by good at $29.73 \%$ and just $10.14 \%$ are in poor state. The Doors has fair as the highest too with $51.84 \%$, follow by poor at $37.84 \%$ and just $24.43 \%$ as good. The Walls has poor as the highest percentage with $41.22 \%$, follow by fair at $32.43 \%$ and the poor at $26.35 \%$. 


\section{Recommendations}

Generally, the problems in the traditional neighbourhoods of Nigerian cities call for the need to formulate a National Urbanization policy. This should be provided within the framework of the National Development plan to attack poverty and social isolation of the people in the core and old area of the cities. In the study area, there are concentrations of dilapidated buildings at the centre of the neighbourhood. It is recommended that this be taken over by new roads, new buildings or open spaces and in order to ensure road safety and convenience in the neighbourhood, general road rehabilitation is recommended and any new development control to the existing satisfactory provisions for achieving effective development control and regulation of buildings. In order to solve housing problems in the neighbourhood, there should be enforcement of provision of facilities like toilets, kitchens, bathrooms and water source at convenient locations by the landlords or owners, while renovation works should be carried out on roofs, windows and doors.

Also, there should be a good network of roads or footpath to link the buildings in the interior of the neighbourhood and basic building regulations should be strictly adhered to.

In addition, there should be provision of public toilets at strategic location by the government.

Lastly, each house should be enforced to have a dustbin and a space should be provided as a collection point by the town council.

\section{Conclusion}

Most people in the old traditional neighbourhood of Nigerian cities live in sub-standard houses and subhuman environments plagued by slums, squalor and the dearth of facilities necessary in houses like potable water, toilets, kitchen, and bathrooms. This impedes sustainable development and leads to poor environmental quality; hence there is the need to upgrade the old traditional neighbourhoods to meet the present day developments. This should be done through the collective efforts of the individual house owners, public agencies, private agencies and non-governmental organizations.

\section{References}

[1]. Akintola, P.O. \& Nyama, H.C. (1978): Land use and surface water pollution in Southwest, Nigeria; proceedings of Regional Conference of International Geographer Union, Lagos, Nigeria. Pp 17-18

[2]. Callans, T.A. (1974): Neighboohoud concept. Owner Felthanham group of papers, Physical planning division, U.S.A. Unpublished P.3

[3]. Keeble, L. (1998): Principles and Practice of Town and Country Planning Estate Gazette. U.S.A. p.33

[4]. Odunjo, O.O., Baba, A.O., \& Adeoye, O.D.(2006): Urban Environmental Sustainability: Upgrading the old Traditional Neighbourhoods in Nigeria cities: A case study of Itamaya Area of Ibadan. Urban design research Team (UDRT), Department of Architecture, School of Environmental Technology, F.U.T.A

[5]. Oguntimehin, A.S.; \& Oguntimehin, O.T.: (2017): An assessment of housing preference determinant in urban center: case study of Lagos metropolis; Journal of Environmental Research, School of Environmental Studies, Federal Polytechnic, Ilaro, Ogun State. Nigeria.

[6]. Olokesusi, F. (2004): Urban Renewal case studies from developing Countries in Urban Renewal in Nigeria. CURP/NISER.

[7]. Onibokun, P., Olokesusi, F., \& Egunjobi, L. (1986): Urban growth and Urban management in Nigeria with particular reference to public utilities ad infrastructure. NISER Report.

[8]. Onokerhoraye, A.G. (1996): The planning implication of the present strcture of Urban Economics in Traditional Nigeria cities. NISER print series. No. 107.

[9]. Sada, P.O. (1980): Growth and decay in Nigeria Cities. The $9^{\text {th }}$ inaugural Lecture, University of Benin. 